\title{
Controls on the distribution of Browns Bank juvenile haddock
}

\author{
David Brickman*
}

\author{
Ocean Sciences Division, Department of Fisheries and Oceans, Bedford Institute of Oceanography, PO Box 1006, \\ Dartmouth, Nova Scotia B2Y 4A2, Canada
}

\begin{abstract}
A combination of biophysical modelling and data analysis is used to infer some important aspects of the southwest Nova Scotia (Canada) - Bay of Fundy (BoF) ecosystem with respect to the first year of life of Browns Bank (BB) haddock. One of the main observations in this ecosystem is that adult fish found in the BoF region consistently exhibit a larger length-at-age than fish found in the $\mathrm{BB}$ region. This is generally thought to be due to drift and retention processes acting during the early life stages, with the larger fish assumed to be the result of settlement in a more favourable temperature and food environment downstream in the BoF. Also, while BB is considered to be an important juvenile nursery ground and the source for the smaller southwest Nova (SWN) fish, the existence of the larger BoF fish suggests a downstream nursery ground. To date, no analysis has been made regarding the whereabouts of such a nursery ground. The assumption of a favourable temperature and food environment in the BoF is investigated. The result of this analysis suggests that the small 'inshore' region off of Yarmouth, Nova Scotia, is the best settling ground. An Age-1 capture probability map is constructed from $30 \mathrm{yr}$ of Canadian research vessel (RV) survey data. This map shows 3 regions where juvenile haddock are found-BB, the inshore, and upstream (northeast) of $\mathrm{BB}$. The average pelagic juvenile concentration field derived from the biophysical model predicts that $\mathrm{BB}$ and the inshore region are preferred settling grounds. A habitat suitability map, based on surficial sediment type, shows that the observed settling grounds coincide with preferred haddock sediment type. Finally, it is shown that the upstream Age-1 fish most likely come from larvae that drifted downstream from the Western Bank haddock spawning ground, and that BB likely acts as a potential source for the Georges Bank haddock stock. Thus, the combination of biophysical modelling and analysis of fisheries data provides evidence of the metapopulation structure of haddock stocks on the Scotian Shelf/Gulf of Maine.
\end{abstract}

KEY WORDS: Metapopulation $\cdot$ Haddock $\cdot$ Biophysical model $\cdot$ Scotian Shelf $\cdot$ Larval drift $\cdot$ Survival

\section{INTRODUCTION}

Browns Bank is the principal spawning ground for haddock (Melanogrammus aeglefinus) on the southwest Nova Scotian shelf, Atlantic Canada. This shelf area is composed of 2 distinct production zones: the Bay of Fundy (BoF) region and the Browns Bank (BB) region; the latter is also known as southwest Nova $(\mathrm{SWN})$. In this paper, a combination of biophysical modelling and data analysis is used to infer some key aspects of the $\mathrm{BB} / \mathrm{BoF}$ ecosystem with respect to $\mathrm{BB}$ haddock. The focus is primarily, but not totally, on processes occurring during the first year of life.
The main geographic and hydrographic features of the Scotian Shelf and Gulf of Maine are presented in Fig. 1. Principal haddock spawning grounds are Georges Bank, Browns Bank and Western Bank, each of these embedded within separate management units (NAFO Divisions 5Z, $4 \mathrm{X}$ and $4 \mathrm{VW}$, respectively). Lesser spawning is thought to occur on Baccaro, LaHave and Emerald Banks (Waiwood \& Buzeta 1989). The region is characterised by a general along shelf flow on the Scotian Shelf which curves north towards the BoF in the SWN region. (The flow field is derived from a run of the finite element model Quoddy4; Lynch et al. 1996, Hannah et al. 2000). Browns and Western 


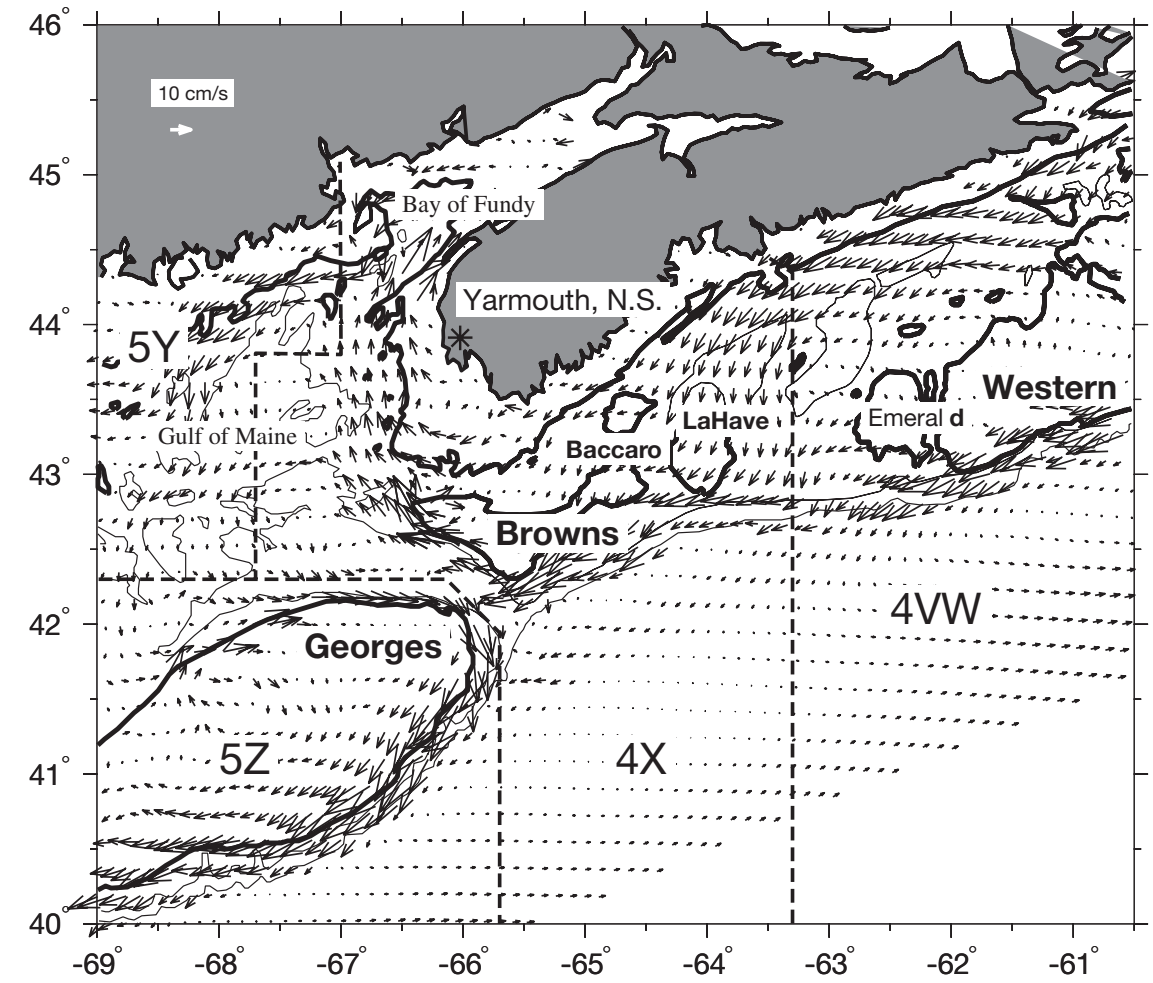

Fig. 1. Climatological spring flow field averaged over the top $20 \mathrm{~m}$ and interpolated onto a $10 \times 10 \mathrm{~km}$ grid. Haddock spawning grounds are labelled in bold text. The main ones are Georges, Browns and Western Banks. Divisions are delineated by dashed lines. The $100 \mathrm{~m}$ isobath is shown in bold. Yarmouth (Nova Scotia) is marked by an asterisk

Banks have weak gyres around them, Georges Bank has a stronger one.

The division of the Scotian Shelf and Gulf of Maine into 3 separate management units, meant to delineate 3 separate haddock stocks, is potentially in conflict with the flow field which can transport haddock larvae between management units, and thus blur this distinction. More precisely, the inshore and shelf break currents provide possible drift pathways linking Western Bank and Browns Bank, and a connection between Browns and Georges Banks is possible via a looping path from Browns, into the Gulf of Maine, and then south to Georges. The Western Bank connection was suggested by Frank (1992).

One of the main observations in the BB/BoF ecosystem is that adult fish found in the BoF region consistently exhibit a larger length-at-age than fish found in the BB region (Hurley et al. 1997). This is generally thought to be due to drift and retention processes acting during the early life stages, with the larger fish assumed to be the result of settlement in a more favourable temperature and food environment downstream in the $\mathrm{BoF}$, and the smaller fish a result of retention and survival in the slower growing BB environment (Wildish et al. 1989, Shackell et al. 1999).
The idea of variable drift and retention setting the size signature in a yearclass begs the question as to whether it is possible to determine what the interannual drift and retention were. An answer to this question was provided by Shackell et al. (1999), who developed an index of early life stage retention and survival based on the Age-2 length-frequency distributions. This motivated Brickman et al. (2001), using an early life stage (or biophysical) model, to investigate whether this signal was a result of processes occurring during the early life stages. Their conclusion was that this was indeed the case.

The above can be taken as a partial summary of the known factors influencing the first years of life of BB haddock. However, parts of this picture are imprecise, or require further investigation. For example, the assumption of a more favourable growth environment in the BoF has not been looked at in great detail. Also, while BB is considered to be an important juvenile nursery ground and the source for the smaller SWN fish, the existence of the larger BoF fish suggests a downstream nursery ground. To date, no analysis has been made regarding the whereabouts of such a nursery ground.

The objective of this paper is to present a coherent picture of the factors influencing the distribution of BB juvenile haddock. The following aspects are considered. First, because drift and retention are so important in this system, a brief review of the Shackell et al. (1999) and Brickman et al. (2001) analyses will be presented. Next, the assumption of a more favourable temperature and food environment in the BoF is looked at in more detail. To determine where juvenile haddock are found, an Age-1 capture probability map is constructed from 30 yr of Canadian research vessel (RV) survey data. As a predictor of settling grounds, an average pelagic juvenile concentration field is derived from the biophysical model and compared to the survey data. To complement this analysis, a habitat suitability map, based on surficial sediment type, is constructed. Finally, data analysis and particle tracking are used to show the connection between Western Bank upstream and Georges Bank downstream. Thus, evidence emerges of the metapopulation structure of haddock stocks on the Scotian Shelf/Gulf of Maine. 


\section{METHODS}

The biophysical model. The biophysical model used is described in detail elsewhere (Brickman \& Frank 2000, Brickman et al. 2001, but see also Heath \& Gallego 1998), and thus will only be outlined here. The model describes the survival and development to hatching of clusters of eggs spawned in the BB region, and the growth and survival of larvae, along trajectories in the flow field. It has 4 main components: (1) a developmental model of the hatching of eggs and growth of larvae, and their vertical position in the water column; (2) an egg production model describing the space/time distribution of spawned eggs; (3) a particle tracking algorithm describing the drift and dispersal of particles representing clusters of eggs and larvae; and (4) a growth and survival model, describing the survival and hatching of eggs, and the growth and survival of larvae. The model outputs space/time distributions of various egg stages, and larval length categories up to the pelagic juvenile stage.

The egg production model spawning duration curve is Gaussian in time, characterised by a peak spawning time, and a spread factor taken to be $20 \mathrm{~d}$. An algorithm describing the time-dependent vertical position of eggs and larvae is included. Clusters of eggs are spawned near the bottom, rise to the surface, then sink and hatch at about the $20 \mathrm{~m}$ level (Page \& Frank 1989). Particles fluctuate around their hatch level during their larval drift. (This algorithm was used for all particle tracking reported in this paper). Mortality is modelled as an exponential function of time. The egg mortality coefficient is constant in space and time $\left(0.2 \mathrm{~d}^{-1}\right)$, while the larval mortality is an inverse function of length (Houde 1997). The circulation model is forced by weekly averaged wind stress and sea level data. The flow field for a given yearday is derived by linear interpolation in space and time of the weekly averaged flow fields (see Brickman \& Frank 2000 for more complete details).

The model used herein differs slightly from the model of Brickman \& Frank (2000). Principal modifications are an increased particle tracking time (90 vs $60 \mathrm{~d})$ and the use of fewer particles (2000 vs 10000 ). The latter was shown to be a satisfactory minimum by Brickman \& Smith (2002), and thus greatly reduces the computational burden of particle tracking. The change to a $90 \mathrm{~d}$ cohort run length allows for a better prediction of potential settling areas, but requires a larval growth equation applicable for longer than the Campana-Hurley age-temperature equation previously used (Campana \& Hurley 1989). Based on the work of Bolz \& Lough (1988), who showed that gadoid larval growth data on Georges Bank could be well modelled up to $150 \mathrm{~d}$ using a Gompertz-type growth curve, a
Gompertz curve was constructed to fit the CampanaHurley equation up to Day 35 (RMS error $=0.17 \mathrm{~mm}$ ), and match the observed $120 \mathrm{~d}$ endpoint length of $\sim 7.7$ to $8.5 \mathrm{~cm}$ (K. Frank pers. comm.). This is similar to what was done by Gallego et al. (1999). This approach, replacing one model equation with another, was considered to be a reasonable method of capturing the essentials of larval growth for extended time periods.

Data sources and analysis. Stratified random surveys have been undertaken annually since 1970 by the Canadian Department of Fisheries and Oceans. Thirty years of July RV bottom trawl data for Division 4X were parsed into (position, number-per-tow) data for the 16 to $-25 \mathrm{~cm}$ window representing the expected length of Age-1 fish. These data were then binned into $25 \times 25 \mathrm{~km}$ grid cells and an average capture success map created by dividing the number of tows with fish in this size class by the total number of tows in the grid cell. Cells with fewer than 10 total tows were discarded. The long averaging period is considered to overcome questions of catchability and create a broad measure of Age-1 haddock distribution.

The annual survey data are also available as lengthfrequency distributions in $2 \mathrm{~cm}$ bins, on a stratum basis. A $30 \mathrm{yr}$ average length-frequency distribution was computed, for 2 strata, by averaging the annual data.

A habitat suitability map was created by hand digitisation of the Canadian Geological Survey map 'Surface Features of the Continental Margin of Eastern Canada' (see Keen \& Williams 1990, companion map 2). The map grades sediment type by coarseness (sandy to muddy) and indicates percentage gravel and boulders. It is taken to provide a rough measure of habitat suitability, with '>90\% sand plus gravel' considered to be prime haddock settling ground (Lough et al. 1989, Tupper \& Boutilier 1995). Much finer resolution maps are currently being produced, but are not yet available for the large area in consideration here.

Other data used come from routine sources, archived at the Bedford Institute of Oceanography. They include bottom temperature data, to indicate the settling temperature environment, and coastal zone colour scanner data, to indicate the spatial distribution of chlorophyll a $(\mathrm{chl} a)$, and thus productivity.

\section{RESULTS}

\section{Drift and retention processes in the $\mathrm{BB} / \mathrm{BoF}$ system}

The idea of a 'leaky gyre' on BB that allows a portion of spawned eggs and larvae to drift downstream has been discussed for close to $20 \mathrm{yr}$ (Campana et al. 1989, Page \& Smith 1989, Smith 1989). Unfortunately, there are few direct measurements of this process. However, 
the larger length-at-age property of BoF fish can be used as a proxy for the proportion of a yearclass that drifted and survived downstream of the BB nursery ground.

Shackell et al. (1999) developed a retention/survival index (RSI) for $\mathrm{BB}$ haddock by deconvolving the annual Age-2 length-frequency distribution from RV survey data into larger BoF and smaller BB lengthfrequency components. The RSI is defined as:

$$
\mathrm{RSI}=\mathrm{BB} /(\mathrm{BB}+\mathrm{BoF})
$$

RSI represents the fraction of a yearclass which was retained and survived in the $\mathrm{BB}$ region. The way that drift and retention are thought to relate to early life stage processes and the RSI is the following (Fig. 2). A variable fraction of the spawned eggs are retained in the $\mathrm{BB}$ region, and the rest drift downstream. The larvae pass through the pelagic juvenile and settling phases with some surviving in the slower growing $\mathrm{BB}$ region and some in the faster growing BoF region. For the first year, the populations remain separate, but by Age- 2 the populations mix and produce a length-frequency distribution whose bimodality represents the proportion of (smaller) fish which were retained and survived in the $\mathrm{BB}$ region versus the fraction which drifted and survived in the BoF region (larger fish). Because most mortality occurs during the first year of life, the RSI can be considered to be a measure of processes occurring during the early life stages.

Brickman et al. (2001) simulated the 14 years of RSI data and computed a model RSI by counting the survivors in the $\mathrm{BB}$ and $\mathrm{BoF}$ regions. There was a signifi-

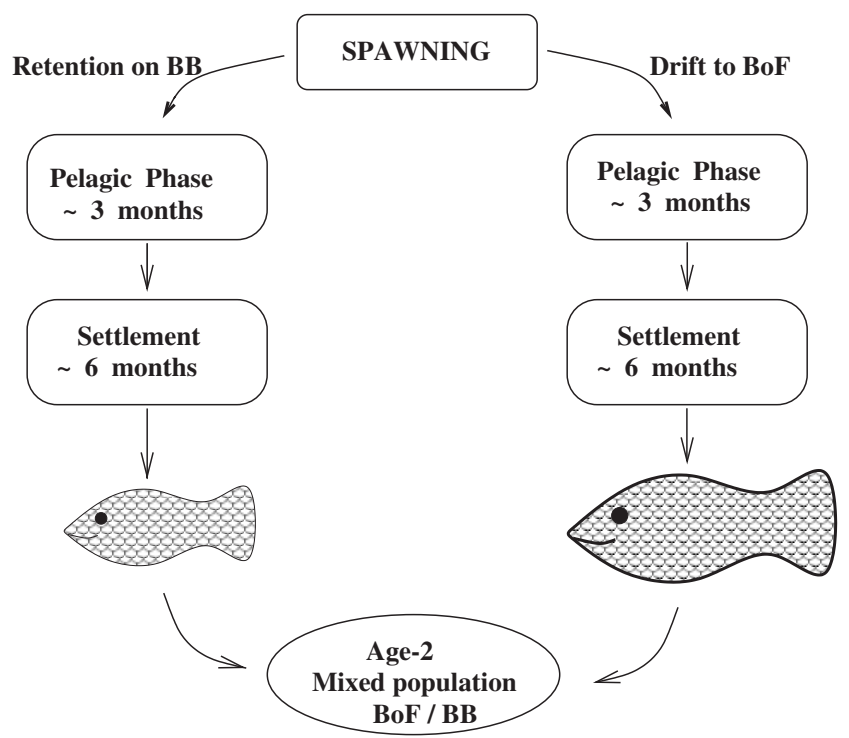

Fig. 2. How drift and retention relates to the Age-2 retection/ survival index (RSI). Banks Bank, BB; Bay of Fundy, BoF. See text for details cant correlation (0.71) between the model RSI and the RSI data, confirming the hypothesis that the size signature of the adult yearclass is determined by processes occurring during the early life stages (see their Fig. 9). The mean model RSI $=0.22$, and was lower than the RSI data $=0.71$. From Eq. (1), this means that on average the model is predicting too many BoF survivors. To correct this requires that there be higher mortality in the $\mathrm{BoF}$ region than in $\mathrm{BB}$. Possible reasons for this will be discussed later.

\section{Evidence for a more favourable growth environment in the BoF}

The faster growth inferred in the BoF is thought to be due to more favourable bottom temperature and food supply in the region. These ideas are essentially unsubstantiated.

The climatological bottom temperature field for July indicates that there is virtually no temperature difference at all along the main drift axis from BB to

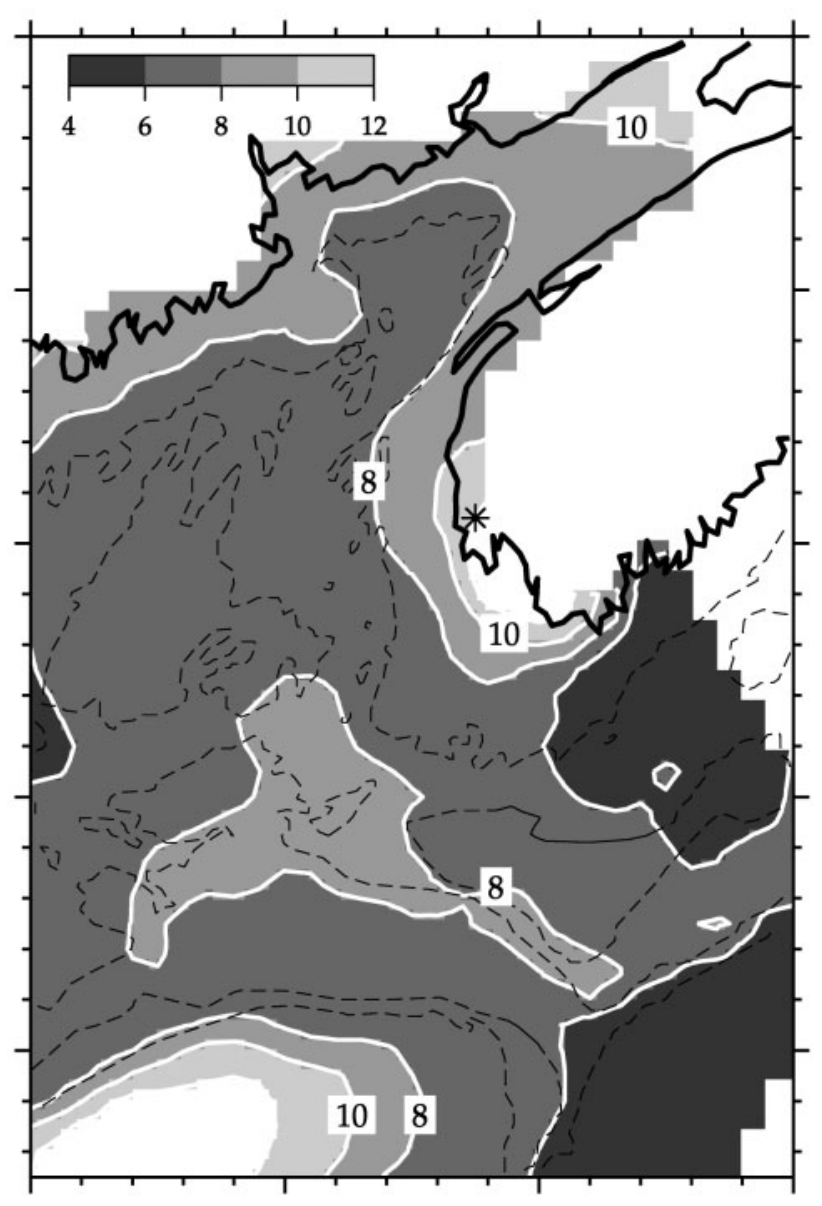

Fig. 3. Climatological July bottom temperature. Yarmouth (Nova Scotia) is marked by an asterisk 


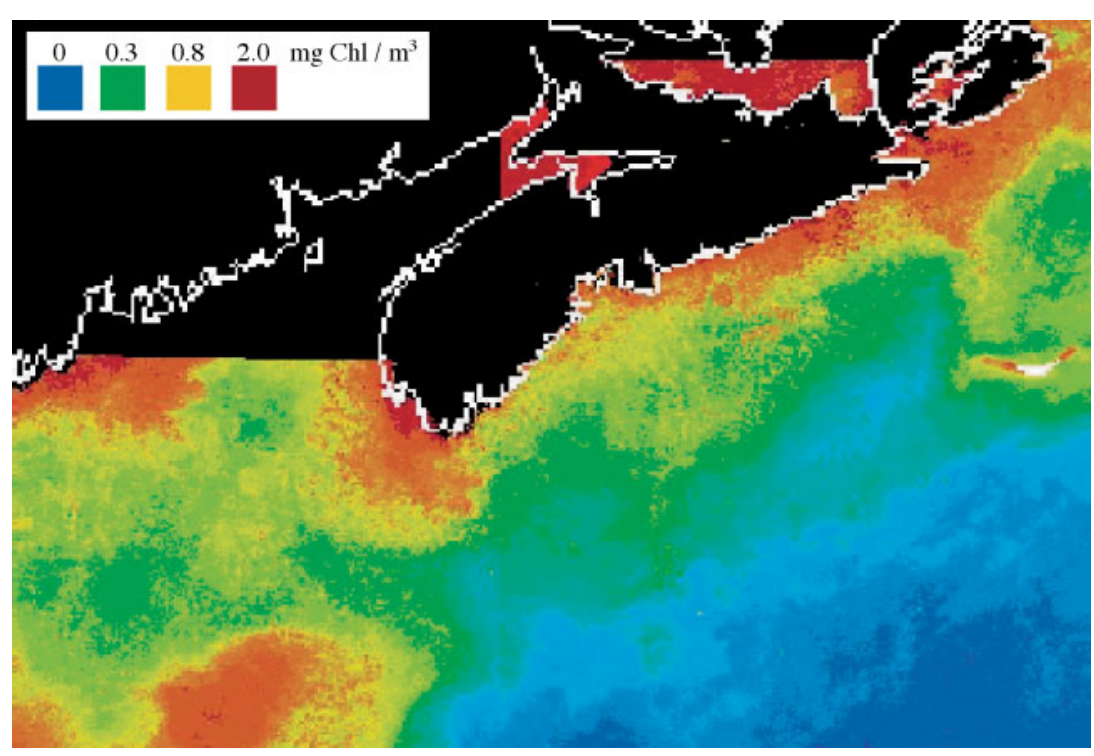

Fig. 4. Climatological July chlorophyll a (chl a) coastal zone colour scanner (CZCS) image. Blacked out region is due to poor data quality questions regarding catchability, an individual summer survey may return a suspect result. Therefore, a detailed picture of the distribution of Age-1 haddock has yet to emerge. To overcome these difficulties and get a rough idea of where the young fish are found, it was decided to average the 30 years of survey data and analyse them from the point of view of the probability of finding an Age-1 fish.

High capture probability areas are found near BB, upstream (i.e. northeast) of the Bank, and in the inshore northwest of Yarmouth (Cape St. Marys) (Fig. 5a). The latter point is deceptive because the survey considers the inshore region to be untrawlable bottom, so Cape St. Marys is the only point surveyed. the mouth of the BoF (Fig. 3). The same basic picture pertains for other summer months. If it is assumed that higher temperatures favour growth, then the small region of the 'inshore' near the southwest tip of Nova Scotia (Yarmouth region) and the upper reaches of the BoF would be the preferred settling locations.

An idea of the primary productivity, and hence the food field, can be inferred from chl a data. An 8 yr average coastal zone colour scan (CZCS) July chl a image is shown in Fig. 4. High productivity regions are seen in the inshore and BoF regions, with lower productivity offshore and near BB. (Due to high turbidity, much of the BoF returns poor data quality and is blacked out by the CZCS analysis routine; however, it is safe to assume that the entire BoF is a high productivity region).

These 2 pieces of information lead to the conclusion that the favourable settling environments in the BoF are the small regions of the inshore and upper reaches of the Bay. Regarding the inshore, this conclusion is consistent with the fact that this area is known to be a region of persistent upwelling, and hence enhanced productivity (Garrett \& Loucks 1976), and supports commercial gadoid and invertebrate fisheries.

\section{Where are Age-1 haddock found?}

There are no regular surveys on the Scotian Shelf designed specifically to sample Age-1 gadoids, although there are some Age- 1 haddock found in the annual 4X summer RV survey. However, because of

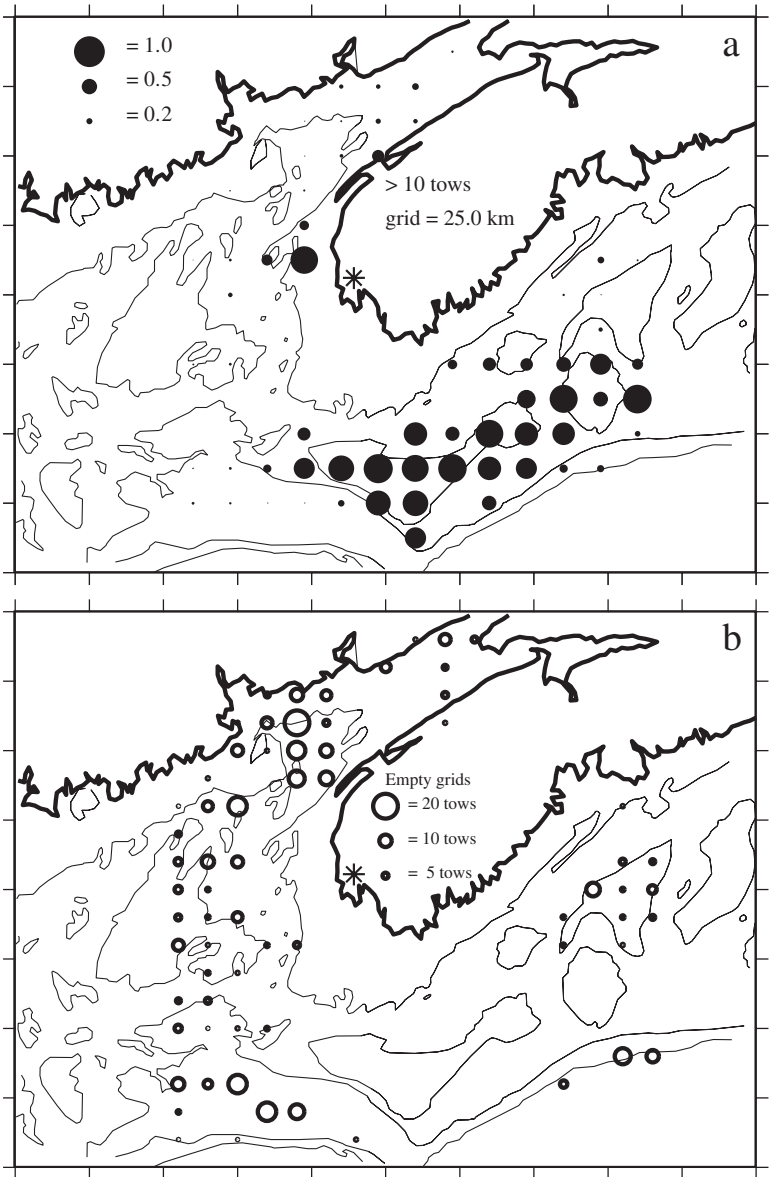

Fig. 5. Age-1 capture success map from research vessel (RV) survey data (1970 to 2000). (a) Average probability of capture, (b) number of tows that never caught an Age-1 sized fish. Yarmouth (Nova Scotia) is marked by an asterisk 
However, industry surveys and catch data show that the whole inshore provides settling ground for juvenile haddock (P. Comeau pers. comm.). Therefore, the inshore should be considered to be a region of high capture probability. Also, there is some capture success in the upper region of the BoF. A notable area with no capture success is the region offshore of Yarmouth where roughly 200 tows were conducted without catching a fish of Age-1 size (Fig. 5b).

Fig. 5 can be considered to be a haddock settlement survivability map. As such, it begs the question as to what determines these settling grounds: is it larval drift, or survivability during the settling phase, or a combination of both? To shed some light on this question, output from the biophysical model was used to create a $25 \mathrm{yr}$ average pelagic juvenile concentration field, as a predictor of settling areas (Fig. 6). The model predicts that the inshore and BB are likely settlement areas as well as the BoF proper. However, in contrast to the capture success result, the model also predicts settlement in the offshore region, and that virtually no juveniles should be found upstream of BB.

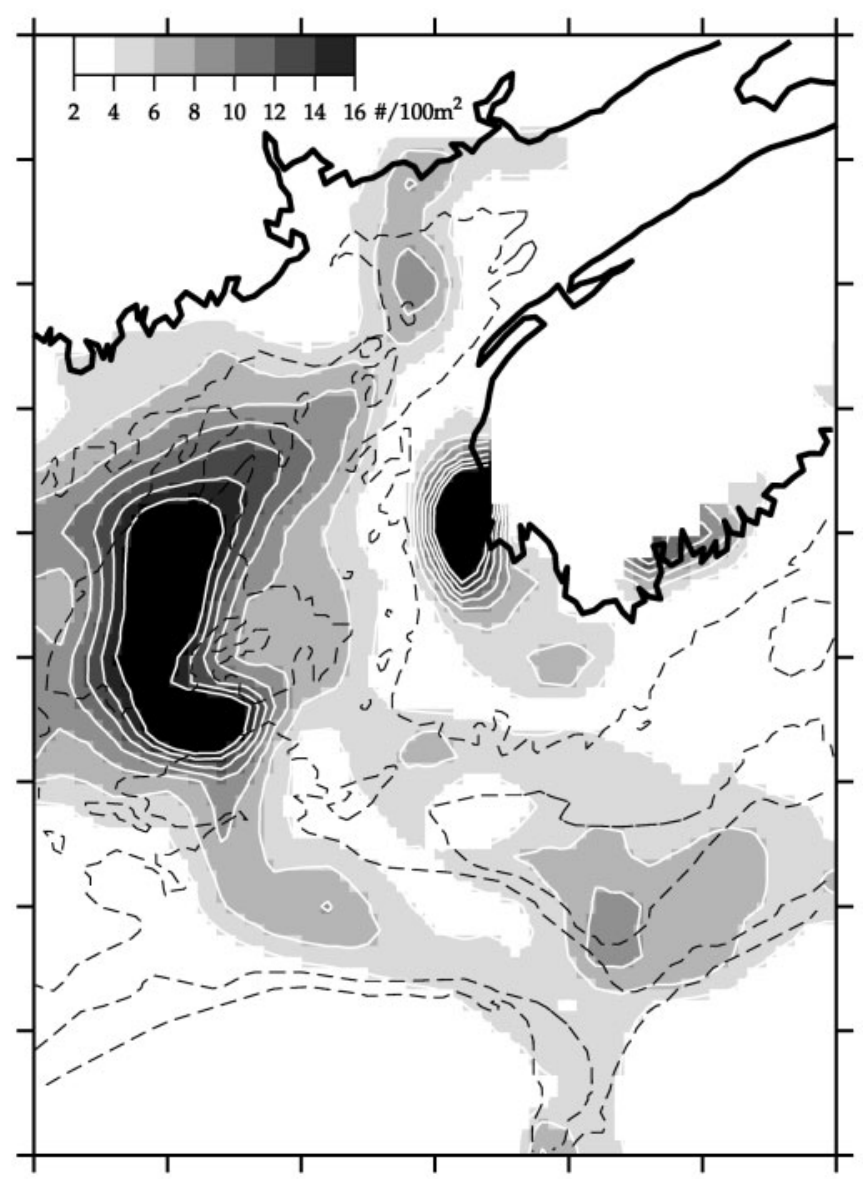

Fig. 6. The $25 \mathrm{yr}$ average pelagic juvenile concentration from the biophysical model. Data has been interpolated and smoothed for plotting purposes

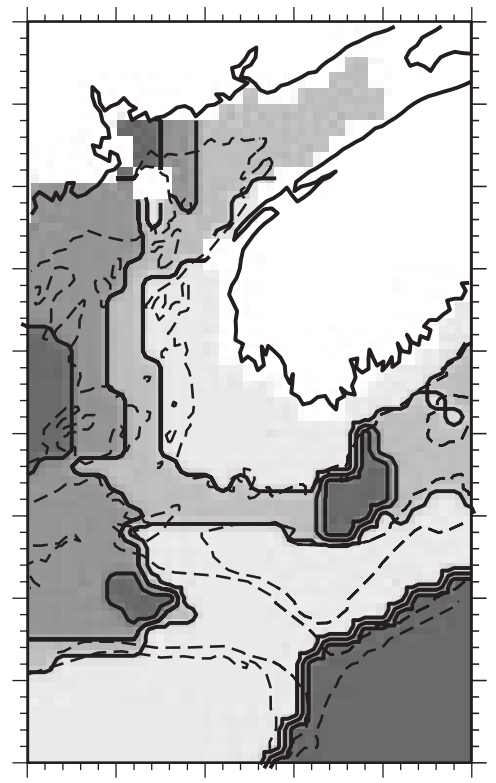

Fig. 7. Habitat suitability map based on surficial sediment type. Note that original data terminate at the left edge of the plot frame

To further investigate these results, a habitat suitability map for the region was created, based on surficial sediment type (Fig. 7). The (discrete) shading scheme goes from light grey $(90 \%$ sand plus gravel, preferred habitat; Lough et al. 1989), to dark grey (mud, $<20 \%$ sand, poor habitat). An almost exact correspondence can be seen between the predominant sand regions and the settlement map (Fig. 5). This suggests that settlement survivability is controlled by habitat type as opposed to other factors such as predation or competition.

The above indicates that there are 2 main nursery grounds for BB haddock. One is the bank itself, the other is the inshore region off of Yarmouth. The BB nursery ground is a slower growth environment due to lower temperatures and productivity, resulting in the smaller length-at-age adult fish. The inshore is a faster growth environment due to higher temperatures and productivity, and is the source for the larger length-atage BoF adults. Final support for this scenario is provided by the $30 \mathrm{yr}$ average Age-1 length-frequency distributions for RV stratum 490 (inshore, Cape St. Marys) and RV stratum 480 (BB) (Fig. 8). As expected, the inshore nursery ground leads to a larger Age-1 juvenile fish (24 cm average length) versus the BB nursery area ( $20 \mathrm{~cm}$ average).

\section{Origin of juveniles found upstream of BB}

The capture success plot (Fig. 5) indicated that Age-1 haddock are found in the area upstream of BB. Although somewhat unclear due to data interpolation and smoothing, the average pelagic juvenile concen- 

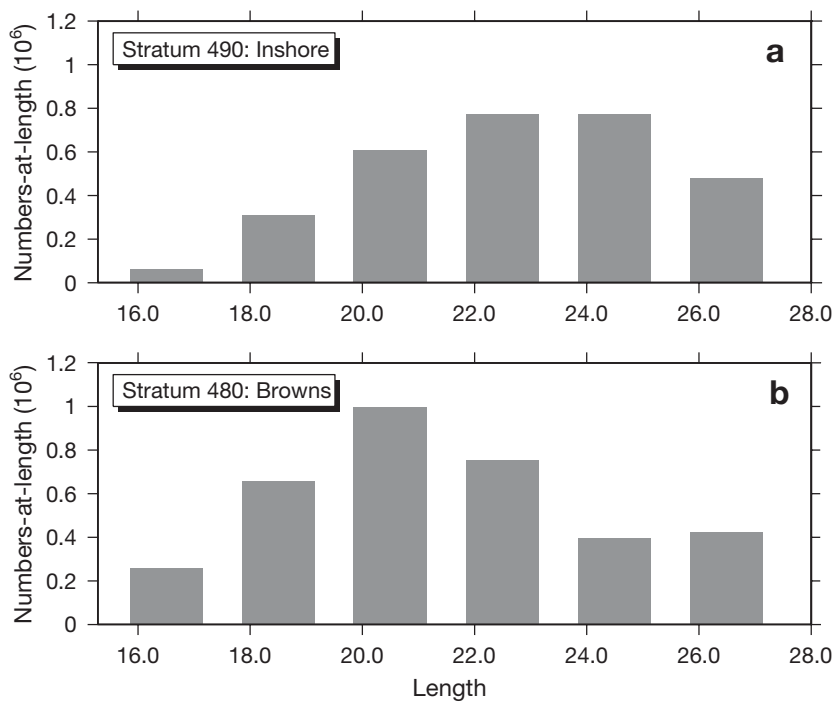

Fig. 8. The 30 yr average Age-1 length-frequency distribution for (a) Cape St. Marys (inshore, RV stratum 490) versus (b) Browns Bank (RV stratum 480)

tration from the biophysical model (Fig. 6) predicts virtually no settlement in this region. In fact, analysis of the raw $90 \mathrm{~d}$ particle tracking data shows that 1529 out of 440640 particles, or $0.35 \%$, end up upstream of BB, and of these, about $70 \%$ occur in years 1978 and 1990. The conclusion is that $\mathrm{BB}$ is not the source for these upstream juveniles. The most likely source for these fish is the upstream spawning ground on Western Bank. The following evidence supports this claim.

Field sampling of ichthyoplankton or pelagic juveniles on the Scotian Shelf is rare, the last field program taking place from 1983 to 1985. An IYGPT (International Young Gadoid Pelagic Trawl) survey from June 1983 finds the centre of mass of the pelagic juvenile distribution upstream of BB (Fig. 9a). Particle tracks from Western and Emerald Banks (Fig. 9b) corroborate Western Bank as the likely source for the pelagic juveniles. What is significant about this year is that earlier ichthyoplankton surveys returned a normal number of eggs, but virtually no larvae near and downstream of BB, leading Koslow et al. (1985) to conjecture that a yearclass failure was occurring. In fact, the Age-1 4X haddock recruitment for that yearclass was normal, and this fact plus an upward revision of the 1983 (VPA; Virtual Population Analysis) yearclass strength for the 4VW (Western) haddock stock led Frank (1992) to conclude that there is also a return migration of adults back to the Western Bank spawning ground.

A possible example of return migration can be seen in the survey data for the 1978 yearclass. The spatial distribution of Ages-1, -2 and -5 across the Scotian Shelf (Fig. 10) shows that for the first 2 ages, there are virtually no fish caught by the survey in division $4 \mathrm{VW}$, sug- gesting significant larval drift from the Western to Browns regions; however, by Age-5, there are more fish found in $4 \mathrm{VW}$ than in $4 \mathrm{X}$. The same data, aggregated as stratified mean number-per-tow for each division (Fig. 11), indicate that the peak in abundance for $4 \mathrm{VW}$ occurs at Age-5, significantly higher than the mean from the 30 years of data (mean age of maximum $=2.87$ ); whereas for $4 \mathrm{X}$, the peak is roughly at the mean age of 2.60. The cohort mortality for $4 \mathrm{VW}$ is 0.35 (calculated by fitting a negative exponential starting from the age of maximum abundance), which is less than the average of 0.44 . For $4 \mathrm{X}$, the mortality is roughly at the mean value of 0.56 . The picture is that larval drift followed by return adult migration manifests as a delayed peak in the abundance-age relationship and a reduced mortality in $4 \mathrm{VW}$. For $4 \mathrm{X}$, mortality is roughly unaffected, indicating that losses to $4 \mathrm{VW}$ are commonplace, or that perhaps, they can be offset by gains due to return adult migration from Georges Bank (see below).

Another illustration of possible drift followed by return migration can be formed by looking at the dif-
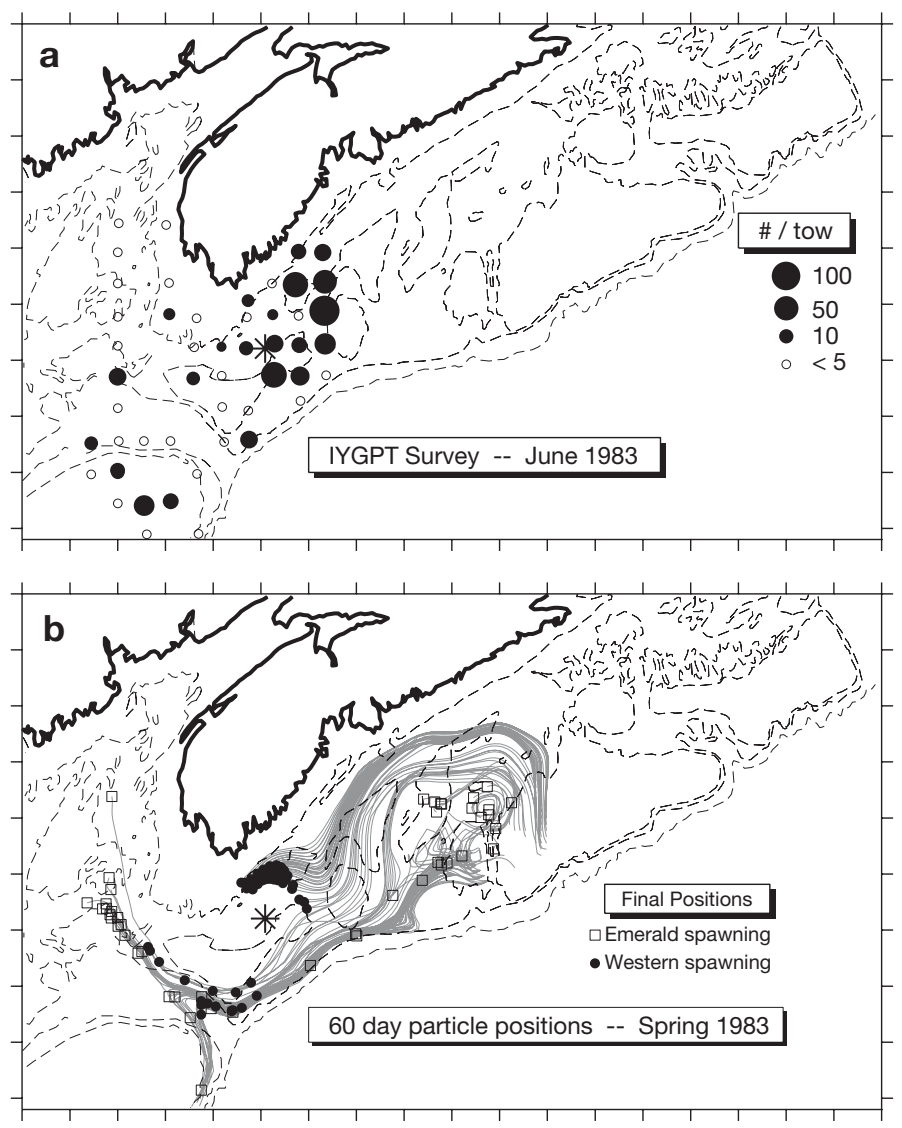

Fig. 9. The 1983 drift from Western to Browns. (a) Pelagic juvenile survey performed by IYGPT in June 1983 (expanding symbol plot). Asterisk marks the centre of mass of distribution. (b) $60 \mathrm{~d}$ particle tracks of the flow field in spring 1983. Particles originated on Western and Emerald Banks. Symbols indicate final positions 

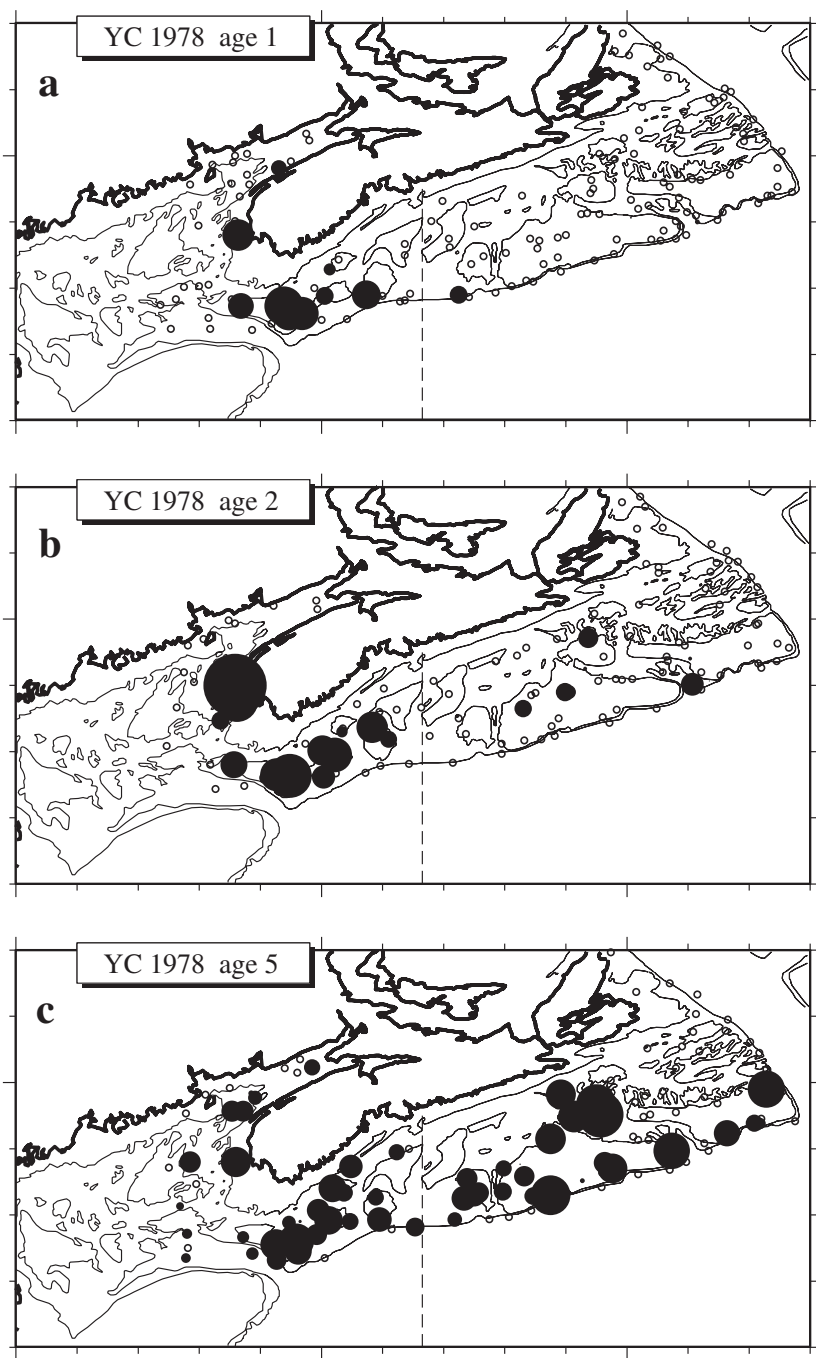

Fig. 10. Spatial distribution of the 1978 year class [yc] Ages-1, -2 and -5 from the RV survey (number-per-tow, log scaled). Empty sets are shown as open circles. The dashed line delineates the 2 NAFO divisions

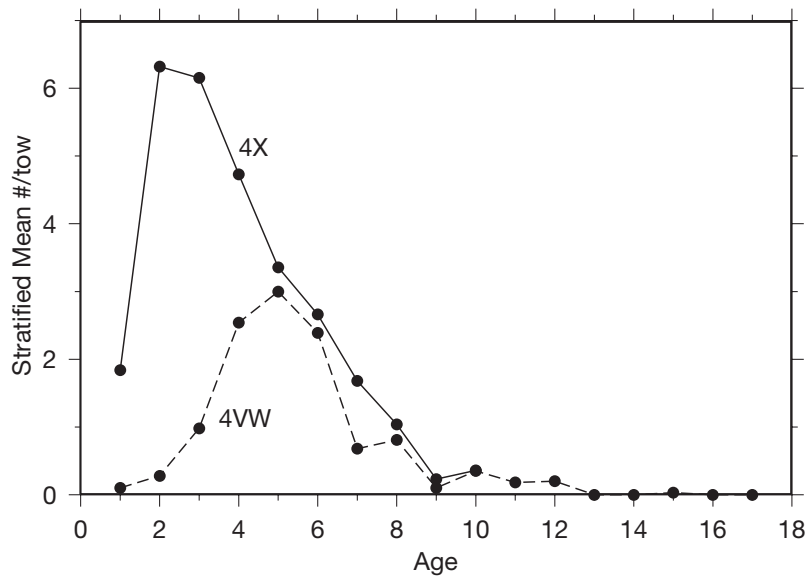

Fig. 11. Stratified mean number-per-tow for the 1978 year class for each division

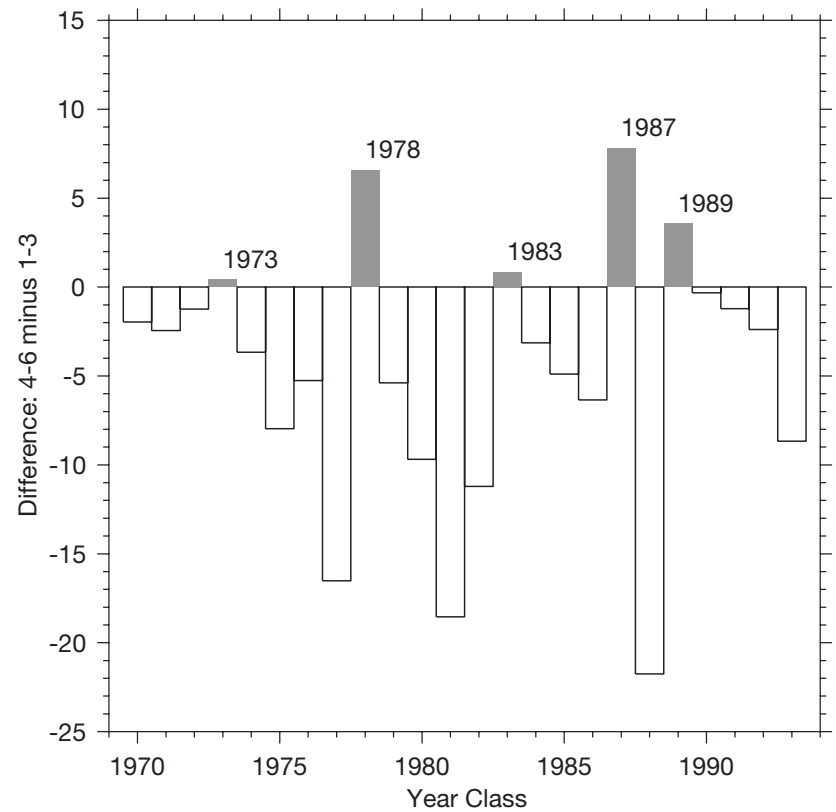

Fig. 12. 4VW RV cohort mean number-per-tow for Ages-4 to -6 minus -1 to -3 , as an index of possible return migration from Browns Bank to Western Bank

ference between the number of adults (Ages-4 to -6) versus the number of juveniles (Ages- 1 to -3 ) in a $4 \mathrm{VW}$ cohort (Fig. 12). There are numerous instances where there are more (or almost more) adults than juveniles in the cohort.

There have been no genetic or juvenile tagging studies of Scotian Shelf haddock, so it is difficult to prove conclusively that larval drift, interstock migration and mixing occur. Scotian Shelf haddock are considered fully recruited at Age-3, so the evidence presented in this section has to be considered in light of possible contamination due to gear effects. Nevertheless, it is considered reasonable to conclude that Western Bank and $\mathrm{BB}$ are connected in a metapopulation sense, whereby larval drift leads to colonisation of BB by juveniles of Western Bank origin, followed by return migration by some adults to the Western Bank spawning stock.

\section{Connection to Georges Bank}

As indicated in Fig. 1, there are drift pathways from BB to Georges Bank, and it is important to find out the degree to which there are crossovers connecting the 2 banks. Particle tracks $(20$ and $60 \mathrm{~d})$ for particles released within the BB spawning ground in the 1975 spring circulation model flow field are presented in Fig. 13. The $20 \mathrm{~d}$ pathway is essentially a wind stress driven short circuit mainly affecting particles in the top $20 \mathrm{~m}$. Qualitative analysis of this pathway indicates that retention of these particles within the Georges 
Bank $100 \mathrm{~m}$ isobath is low, and thus this crossover is likely of little biological relevance. More important biologically is the longer timescale ( $\geq 60 \mathrm{~d}$ ) pathway (Fig. 13b) as surviving larvae of this age would be more likely to settle on Georges Bank.

To get a quantitative idea of the potential significance of Browns-to-Georges crossovers, a probability density function (pdf) was created describing the probability that a particle released in the BB spawning ground is found within the Georges Bank $100 \mathrm{~m}$ isobath. The probability is calculated by counting the number of particles within the $100 \mathrm{~m}$ isobath at a given time and dividing by the total number of particles initially released. Because the flow field changes with yearday, the crossover probability in a given year will be a function of the time of release and the number of days of drift. A typical example, in the form of an expanding
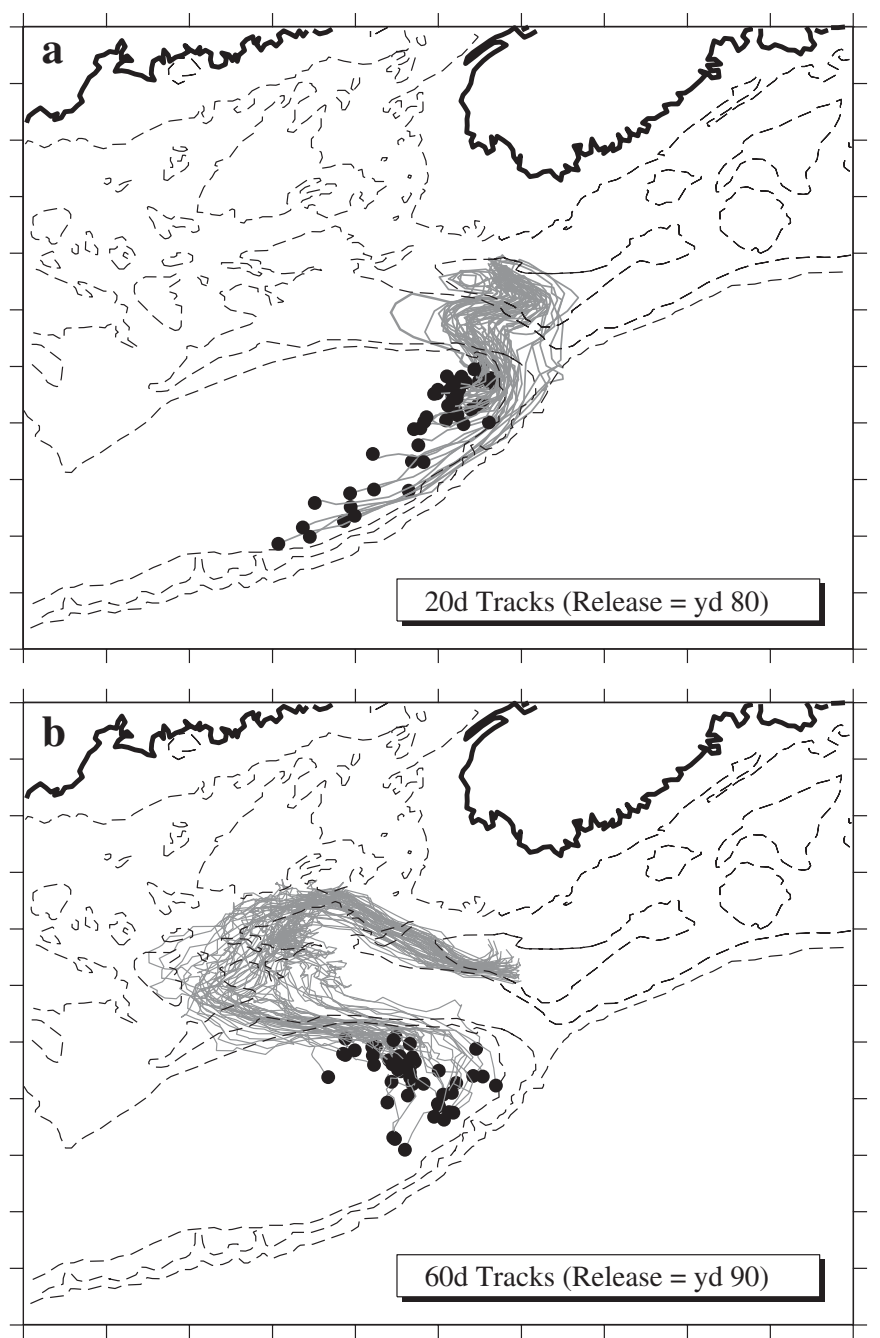

Fig. 13. Particle tracks showing (a) the $20 \mathrm{~d}$ fast crossover path from Browns Bank to Georges Bank and (b) the more biologically relevant $60 \mathrm{~d}$ path. Flow fields are from spring 1975. Symbols mark the end points of the trajectories. yd: yearday

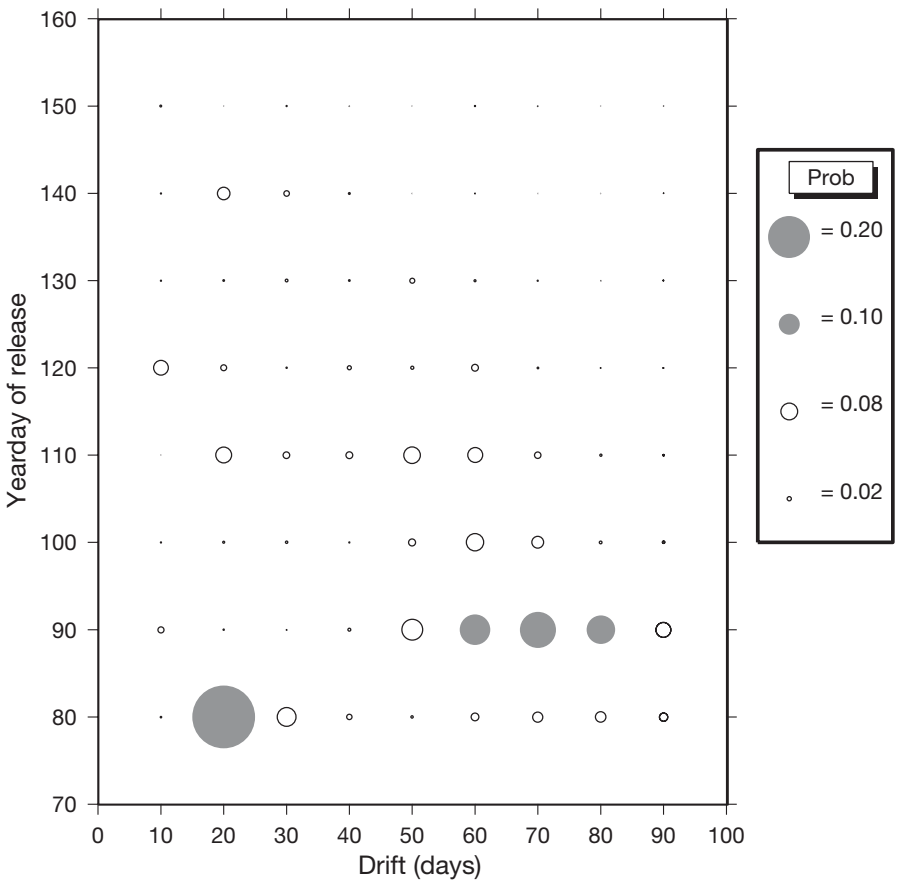

Fig. 14. A probability density function (pdf) for crossover from the Browns Bank spawning ground to Georges Bank. Flow field is for 1975

symbol plot, is shown in Fig. 14. Following a line of constant yearday of release, it is seen, for example, that the yearday 80 release exhibits the $20 \mathrm{~d}$ crossover (with $\mathrm{p}=$ 0.30 ) which decreases to virtually 0 retention by $50 \mathrm{~d}$ of drift, after which there is a slight increase in the number of particles on Georges Bank, representing the longer timescale crossover. The yearday 90 release has no short timescale connection, but shows a relatively high crossover probability for drift greater than $50 \mathrm{~d}$. The plot also shows that the majority of crossovers occur for releases early in the year (mid- to late March). This observation was typical of most years.

To summarise the crossover potential on an interannual basis, the yearly maximum pdf for drift longer than $55 \mathrm{~d}$ for years 1970 to 1993 was computed (Fig. 15). About $1 / 3$ of the years have a maximum pdf of greater than 0.4 , with some years having release days with greater than $60 \%$ probability of crossover. The indication is that BB can act as a significant source of larvae for the Georges Bank haddock stock.

\section{DISCUSSION}

In this paper, a combination of biophysical modelling and data analysis was used to create a picture of the BB haddock ecosystem. Before the pieces are put together, a few outstanding questions should be addressed. 


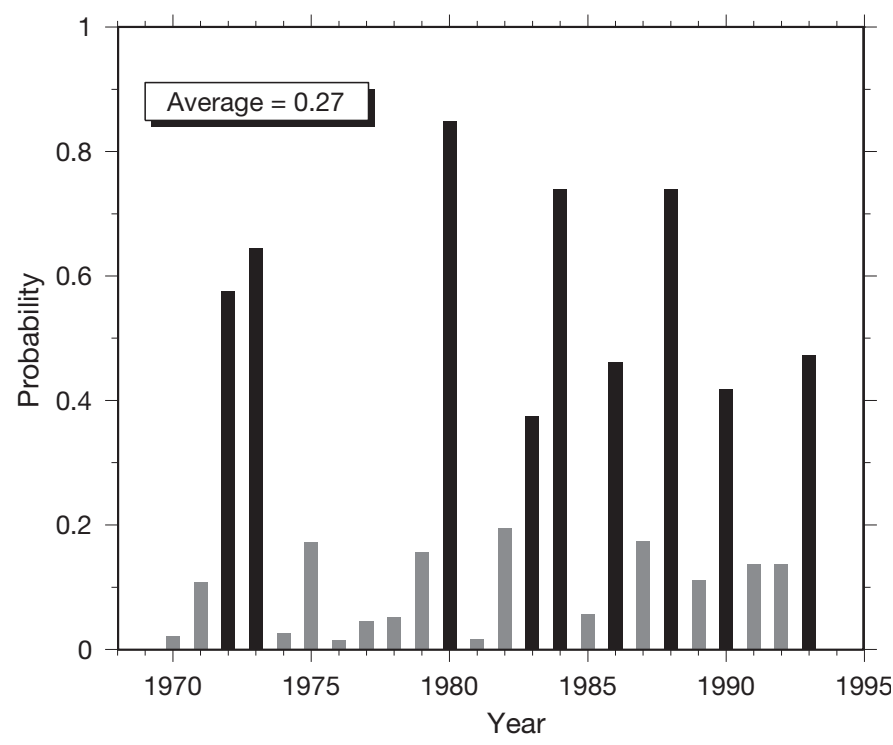

Fig. 15. Maximum probability for drift from Browns Bank spawning ground to Georges Bank. NB: release times are between yearday 80 and 150, and probability is for drift $>55 \mathrm{~d}$. Dark shading denotes years with probability greater than the average $(0.27)$

As noted, the biophysical model retention/survival analysis yields an average model RSI lower than that of the RSI data. To reconcile this fact, Shackell et al. (1999) and Brickman et al. (2001) concluded that a differential mortality is required between the BoF and $\mathrm{BB}$ regions, with higher mortality in the BoF region needed to bring the model results more in line with the data.

What could be the cause of such mortality? Three possibilities come to mind. First, Frank \& McRuer (1989) found a positive relationship between haddock larval condition and water column vertical stratification. Therefore, larvae drifting into the inshore region, where tidal mixing decreases stratification, likely arrive in relatively poor condition. It is interesting to note that this tendency for haddock larvae to prefer lower turbulence, higher stratification environments is in contrast to herring larvae found in the same region who prefer the increased turbulence inshore region (Muelbert et al. 1994), and points out that the degree to which turbulence enhances feeding rates may be species dependent. Second, the bottom topography in the inshore is rugged-considered as 'untrawlable bottom' in the stratified random RV sampling scheme, although trawlable by fishers who know the area. Therefore, suitable sand and gravel settlement substrate may occur in isolated pockets and be difficult for settling juveniles to find. Finally, in general, the inshore ecosystem is known to be highly productive, and thus competition and predation pressures are likely higher. For example, Suthers \& Frank (1990) found an inverse relationship between ctenophore abundance and large $(>1 \mathrm{~mm})$ zooplankton biomass with higher ctenophore abundance (lower large zooplankton) in the inshore region. Thus, competition for a common food resource may reduce its effective availability to post-larval haddock. All of the above processes are not included in the biophysical model, but could contribute to a higher early life stage mortality despite settling in a more productive area.

Recall that the biophysical model indicates that BB and the inshore are likely settling grounds, but also predicts significant settlement should occur in the offshore (Fig. 6) - a prediction not supported by the Age-1 settlement map (Fig. 5). This indicates either that: (1) the model larval drift calculation is correct, and there is high mortality in the post-larval or settlement phase; or (2) the model drift and/or survival calculation is incorrect. The former possibility is somewhat supported by the habitat suitability map (Fig. 7), which suggests that the substrate is unsuitable for juvenile haddock. With respect to the latter, it is possible that the model flow fields are in error, but general agreement with observations (Hannah et al. 2000, 2001) makes it unlikely that this is the main reason. Another possibility is that larval behaviour, e.g. diel vertical migration, affects their distribution. However, preliminary investigations by the author have indicated that this is unlikely to be the case. Lastly, it is possible that there is high larval mortality not captured by the model. Although not definitive, the fact that the offshore has lower productivity (Fig. 4) suggests that food availability may be the reason for this apparent mortality. Clearly, further work is needed to resolve this discrepancy.

The Age-1 capture success map (Fig. 5) shows a significant probability of finding juvenile haddock upstream of BB. This should not be confused with a statement regarding abundance, as the average RV number-per-tow is 17 in the upstream region versus 45 on $\mathrm{BB}$ and the inshore. The fact that the average capture success is the same in the 2 regions (42\%) indicates that while Western Bank is not on average a major contributor numerically to the BB haddock stock, the frequency of drift and survival from Western to Browns is quite high.

The information presented in the previous sections leads to the following schematic of the BB haddock ecosystem (Fig. 16): each year roughly $10^{13}$ eggs are spawned on BB (Brickman \& Frank 2000). A fraction of them are retained by the BB gyre where they develop through larval and pelagic juvenile stages to settle near the bank. The BB nursery ground is a relatively slower growth area and leads to smaller length-at-age adults. A fraction of the eggs drift downstream where they split into 2 main groups. One group drifts into the 


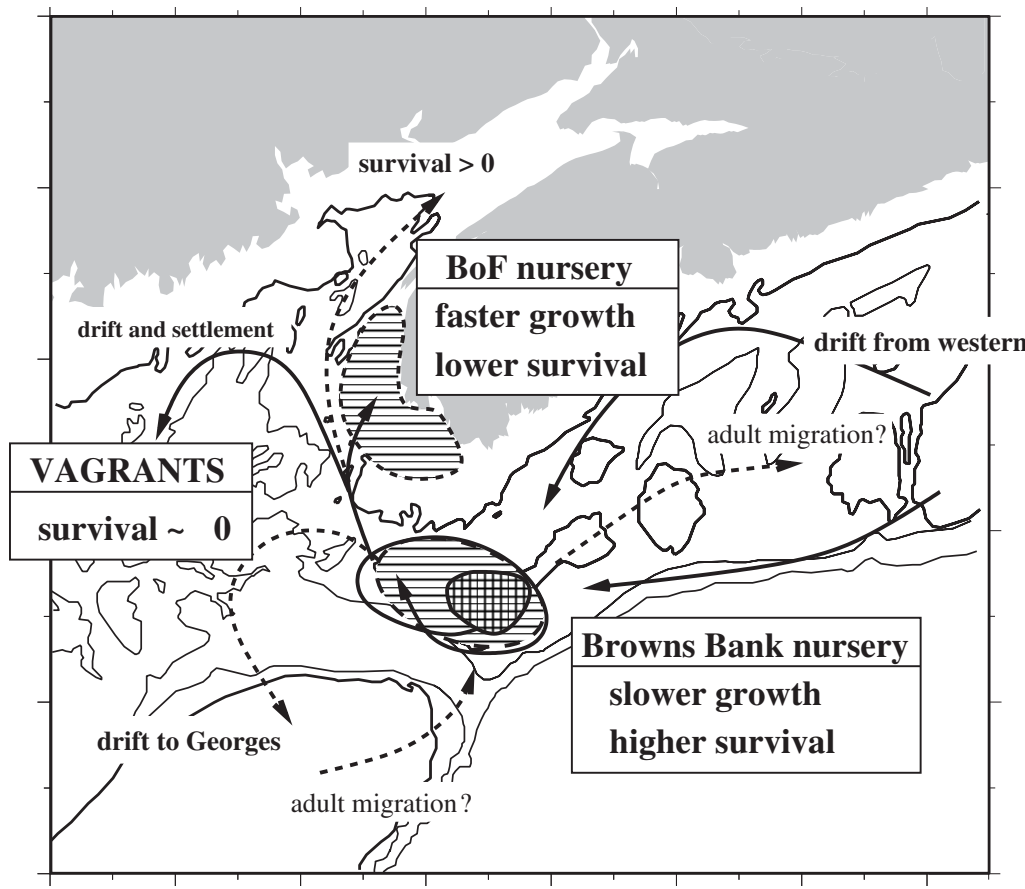

Fig. 16. Schematic of BB haddock ecosystem. Main spawning ground is cross-hatched. Settling grounds are hatched horizontally. See text for details

inshore region where survivorship is lower, but those that do survive develop in a warmer, more productive area, and thus grow faster. A small fraction of this group drift and settle in the upper reaches of the BoF. The other main group drift offshore where survivorship is very low. A fraction of these offshore 'vagrants' (Sinclair 1988) drift onto Georges Bank where they become members of the Georges Bank haddock stock. Although the average number of survivors along this pathway has not yet been estimated, particle tracking results indicate that there are times when this is a highly probable route (Fig. 15), and thus it is likely that BB serves as an episodic source of recruits to the Georges Bank stock. Age-1 haddock are found upstream of $\mathrm{BB}$, and modelling plus analysis of survey data show that the source is almost certainly the Western Bank spawning ground, and that return adult migration also occurs.

The idea that there are 2 viable nursery grounds for the BB haddock stock is a variant of the membervagrant hypothesis of Sinclair (1988) (see also Iles \& Sinclair 1982). In this case, larvae can be 'vagrant' from the spawning ground nursery area, but still end up a 'member' of another viable nursery ground. True vagrants drift toward the offshore, with little apparent survivorship. However, even some of this vagrant cohort likely become members of a different population, that of Georges Bank. Finally, periodically, there is larval drift and successful juvenile settlement in the $\mathrm{BB}$ region of eggs spawned on Western Bank. Thus, the BB haddock population does not exist in isolation, but rather as part of a population-of-populations, or metapopulation, system that links the 3 main haddock stocks on the Scotian Shelf and Gulf of Maine.

It is interesting that the metapopulation model that emerges is different from the classical Levins-type model in which patch recolonisation is often modelled as a stochastic, or essentially diffusive-like, process (see Hanski \& Gilpin 1997). In the ocean, early life stages are released into currents that have a mean component to them which transports a portion of larvae downstream from their spawning site. Thus, dispersion occurs in a directed fashion. The metapopulation model has a component to it which is like a conveyor belt, with currents transporting potential colonisers downstream, and occasional homing-type return migration of a portion of the adults to their original spawning grounds. The combination of biophysical modelling and analysis of fisheries data can be used to quantify these effects.

Acknowledgements. The author thanks Drs. N. Shackell and K. Frank for discussions and suggestions during the writing of this manuscript. The comments of 2 anonymous reviewers helped improve the final text.

\section{LITERATURE CITED}

Bolz GR, Lough RG (1988) Growth through the first six months of Atlantic cod, Gadus morhua, and haddock, Melanogrammus aeglefinus, based on daily otolith increments. Fish Bull (Wash DC) 86:223-235

Brickman D, Frank KT (2000) Modelling the dispersal and mortality of Browns Bank egg and larval haddock (Melanogrammus aeglefinus). Can J Fish Aquat Sci 57: 2519-2535

Brickman D, Smith PC (2002) Lagrangian stochastic modelling in coastal oceanography. J Atmos Ocean Technol 19:83-99

Brickman D, Shackell NL, Frank KT (2001) Modelling the retention and survival of Browns Bank haddock larvae using an early life stage model. Fish Oceanogr 10:284-296

Campana SE, Hurley PCF (1989) An age- and temperaturemediated growth model for cod (Gadus morhua) and haddock (Melanogrammus aeglefinus) larvae in the Gulf of Maine. Can J Fish Aquat Sci 46:603-613

Campana SE, Smith SJ, Hurley PCF (1989) A drift-retention dichotomy for larval haddock (Melanogrammus aeglefinus) spawned on Browns Bank. Can J Fish Aquat Sci 46 (Suppl 1):93-102

Frank KT (1992) Demographic consequences of age-specific dispersal in marine fish populations. Can J Fish Aquat Sci 11:2222-2231 
Frank KT, McRuer JK (1989) Nutritional status of fieldcollected haddock Melanogrammus aeglefinus larvae from southwestern Nova Scotia: an assessment based on morphometric and vertical distribution data. Can J Fish Aquat Sci 46(Suppl 1):125-133

Gallego A, Heath MR, Wright P, Marteinsdottir G (1999) An empirical model of growth in the pelagic early life history stages of north Sea haddock. ICES-CM 1999-Y:13:1-9

Garrett CJR, Loucks RH (1976) Upwelling along the Yarmouth shore of Nova Scotia. J Fish Res Board Can 33: $116-123$

Hannah CG, Shore JA, Loder JW, Naimie CE (2000) Seasonal circulation on the central and western Scotian Shelf. J Phys Oceanogr 31:591-615

Hannah CG, Shore JA, Loder JW (2001) The drift-retention dichotomy on Browns Bank: a model study of interannual variability. Can J Fish Aquat Sci 57:2506-2518

Hanski IA, Gilpin ME (1997) Metapopulation biology. Academic Press, San Diego, CA, p 512

Heath M, Gallego A (1998) Bio-physical modelling of the early life stages of haddock, Melanogrammus aeglefinus, in the North Sea. Fish Oceanogr 7:110-125

Houde ED (1997) Patterns and trends in larval-stage growth and mortality of teleost fish. J Fish Biol 51(Suppl A):52-83

Hurley PCF, Black GAP, Mohn RK, Comeau P (1997) Assessment of 4X Haddock in 1996 and the first half of 1997. DFO Can Stock Assess Secretariat Res Doc 97/108

Iles TT, Sinclair M (1982) Atlantic herring: stock discreteness and abundance. Science 215:627-633

Keen MJ, Williams GL (1990) Geology of Continental margin of eastern Canada. Geological Survey of Canada, Ottawa

Koslow JA, Brault S, Dugas J, Page F (1985) Anatomy of an apparent year-class failure: the early life history of the 1983 Browns Bank Haddock (Melanogrammus aeglefinus). Trans Am Fish Soc 114:478-489

Lough RG, Valentine PC, Potter DC, Auditore PJ, Bolz GR, Neilson JD, Perry RI (1989) Ecology and distribution of juvenile cod and haddock in relation to sediment type and

Editorial responsibility: Otto Kinne (Editor),

Oldendorf/Luhe, Germany bottom currents on eastern Georges Bank. Mar Ecol Prog Ser 56:1-12

Lynch D, Ip J, Naimie C, Werner F (1996) Comprehensive coastal circulation model with application to the Gulf of Maine. Cont Shelf Res 16:875-906

Muelbert JH, Lewis MR, Kelley DE (1994) The importance of small-scale turbulence in the feeding of herring larvae. J Plankton Res 16:927-944

Page FH, Frank KT (1989) Spawning time and egg stage duration in Northwest Atlantic haddock (Melanogrammus aeglefinus) stocks with emphasis on Georges and Browns Bank. Can J Fish Aquat Sci 46(Suppl 1):68-81

Page FH, Smith PC (1989) Particle drift in the surface layer off southwest Nova Scotia: description and evaluation of a model. Can J Fish Aquat Sci 46(Suppl 1):21-43

Shackell NL, Frank KT, Petrie B, Brickman D, Shore J (1999) Dispersal of early life stage haddock (Melanogrammus aeglefinus) as inferred from the spatial distribution and variability in length-at-age of juveniles. Can J Fish Aquat Sci 56:1-12

Sinclair M (1988) Marine populations: an essay on population regulation and speciation. University of Washington Press, Seattle

Smith PC (1989) Circulation and dispersion on Browns Bank. Can J Fish Aquat Sci 46:539-559

Suthers IM, Frank KT (1990) Zooplankton biomass gradient off south-western Nova Scotia: nearshore ctenophore predation or hydrographic separation? J Plankton Res 12: 831-850

Tupper M, Boutilier RG (1995) Effects of habitat on settlement, growth, and postsettlement survival of Atlantic cod (Gadus morhua). Can J Fish Aquat Sci 52:1834-1841

Waiwood KG, Buzeta MI (1989) Reproductive biology of southwest Scotian shelf haddock (Melanogramus aeglefinus). Can J Fish Aquat Sci 46(Suppl 1):153-170

Wildish DJ, Wilson AJ, Frost B (1989) Benthic macrofaunal production of Browns Bank, northwest Atlantic. Can J Fish Aquat Sci 46:584-590

Submitted: April 8, 2002; Accepted: August 29, 2003

Proofs received from author(s): October 28, 2003 